\title{
RESISTANCE WELDING: INTRODUCTION AND RECENT DEVELOPMENTS
}

\section{S. TRIPATHY* \& AJITAV SAHOO}

ITER, Siksha 'O'Anusandhan Deemed to be University, Bhubaneswar, Odisha, India

\begin{abstract}
Aim of this paper is to discuss about the in-opposition welding and the ongoing advancement in same zone. Procedure may include current as much as few kilo ampere and voltage of 2 to 12 volts. Weight, current and voltage necessity differ from plate to plate as their thickness and material changes in an opposition welding process there are two anodes made of copper or tungsten or any of their combination. These materials are picked on the grounds that they have high electrical conductivity and they don't twist much when there temperature is raised. Spot welding is a standout amongst the most ordinarily utilized opposition welding in view of prerequisite of welding slender sheets with one another in huge number of modern application for instance downpour mentor fabricating, body of a vehicle and some more. there are a lot more opposition welding forms like crease welding, projection welding, streak welding, upset butt welding, high recurrence obstruction welding, high recurrence enlistment welding. AC is supply is most acclaim out of these three on account of its effortlessness. DC supply can utilized where substantial measure of current is required. in this procedure there are two cathodes one of which is stationary and the other is mobile. Mainly this operation is used in manufacturing industry for welding of various materials for better performance.
\end{abstract}

KEYWORDS: Welding, Frequency \& Materials

Received: Apr 17, 2019; Accepted: May 07, 2019; Published: Jun 12, 2019; Paper Id.: IJMPERDJUN2019177

\section{INTRODUCTION}

There are two welding forms one in which warmth and weight is connected and other in which just warmth is connected. Opposition welding is of first kind which is went with weight[1]. It is a basic procedure in which a sheet of metal which should be welded is held between two terminals and current is gone through them for a brief timeframe[2]. This present delivers substantial measure of warmth which can be found by connection $H=R T\left(I^{\wedge} 2\right)$. Procedure may include current upto few kilo ampere and voltage of 2 to 12 volts. Weight, current and voltage necessity shift from plate to plate as there thickness and material changes in an opposition welding process there are two anodes made of copper or tungsten or any of their amalgam[3]. These materials are picked in light of the fact that they have high electrical conductivity and they don't misshape much when there temperature is raised. spot welding is a standout amongst the most generally utilized opposition welding due to necessity of welding slender sheets with one another in huge number of mechanical application for instance downpour mentor producing, body of a vehicle and some more. There are a lot more opposition welding forms like crease welding, projection welding, streak welding, upset butt welding, high recurrence obstruction welding, high recurrence acceptance welding[4]. Last three welding process are not normal as they are just utilized in the particular spot for instance upset butt welding is utilized for joining shaft start to finish with one another. the spot welding is the most widely recognized type of the opposition welding as this procedure has expansive number of utilizations in the businesses for instance welding sheets in mentors of trains and vehicles for generation of body. 


\section{Improvement in Gas Metal Arc Fastening}

The motorized GMAW method is presently the foremost typically used fastening method for expansive dimension transmission pipelines and there are numerous late fastening technique advancements that have improved potency. nevertheless, broad utilize upcountry and for bump off, it's been incontestible cheap for Jlay institution[5]. The GMAW procedure thus speaks to this innovative and speaks to the benchmark against that alternative fastening forms are evaluated. The money matters of pipeline development square measure determined by 2 components of the pipeline fastening strategy: Continuous analysis is exploring novel procedures that address all of those regions.

\section{Improvements in GMAW Root Pass Techniques}

A high reputability root dot with a sleek internal profile is basic creases of gas and oil pipelines[6]. The basis run is often the speed dominant procedure in transmission pipeline development, and therefore, the fastening is commonly performed utilizing AN inner fastening machine or an enclosed line-up clip with copper backing. All framework are displayed to offer satisfactory fastening creation rates to most pipelining applications[7,8]. Be that because it might, on account of very little activity pipe and movement creases in larger dimension lines the employment of within fastening frameworks is unimaginable and single sided. Outside methodology should be embraced. In manual fastening, this is often cultivated by utilizing a 'key holding' strategy with a polyose anode. However, as of shortly one the most solid possibility for GMAW was the employment of AN inner support framework. Previous work by one of the creators incontestible that controlled plunge exchange may be used store high honesty root keeps running within the dainty divider pipe. An ordinary giant scale phase of a root run is appeared in Figure one[9]. Full pipe welds to possess been created, and techniques are created and met all needs for X80 pipe obsessed with this controlled exchange root and beat exchange fill passes. The procedure resistances for absence of combination were fully investigated over a large scope of heat inputs. High Deposition GMAW Full Pass Developments Although the fill passes do not management advancement of the pipeline development, the proficiency of fill and high procedures decides the final joint fulfilment rates, and therefore, the amount of fill stations needed. They wrestle increasing noteworthiness because the pipe divider thickness and breadth increment. The money usefulness of diverse future undertakings depends upon the capability to end the fill goes with as very little pipeline unfold as conceivable to minimize work, and hardware prices. Created in 1969, the primary GMAW motorized fastening frameworks used a solitary light-weight and wire feed. Aminoalkanoic acid Dasa's Saturnax fastening framework was the most motorized GMAW gear to utilize double lights for pipeline development. This fastening head needs less fastening stations because it stores 2 passes at identical time, and it's been used wide upcountry and seaward. Some pipeline's temporary staff presently provide double light-weight fastening hardware albeit single-burn frameworks still stay the foremost loosely used. With funding from BP Exploration and Transcend Pipelines, Coalfield University's fastening Engineering research facility has been making a double a few of GMAW to decrease the amount of fill and high fastening stations needed, and their CAPS (Cranfield automatic Pipewelding System) have currently been effectively field tried at RMS fastening Systems in Canadian winter conditions [10,11]. A couple of GMAW contrasts from ancient GMAW as 2 fastening wires square measure more experienced an analogous fastening light-weight. A solitary light-weight with 2 contacts tips is used to encourage the 2 wires into a solitary weld pool. Though the aptitude of the multi-wire GMAW method was initial investigated as earlier than schedule because the Nineteen Fifties, it's not clad to being financially sensible till typically as these days as a result of execution impediments associated with the ability supply innovation, that led to procedure hazards. The Cranfield automatic Pipewelding System (CAPS) utilizes 2 couple burns on 
a solitary carriage (double combine welding). The combine GMAW permits high fastening paces, and 2 passes square measure keep at identical time, that more diminishes fastening times. In gazing fastening frameworks for AN in progress task gauge, CAPS led to a twenty-fifth economical fastening prices once contrasted and standard automatic GMAW frameworks.

In this procedure there are a few sections which are appeared in the figure underneath. this framework is utilizing single stage AC supply control supply it very well may utilize three stage air conditioning supply or DC current[11].

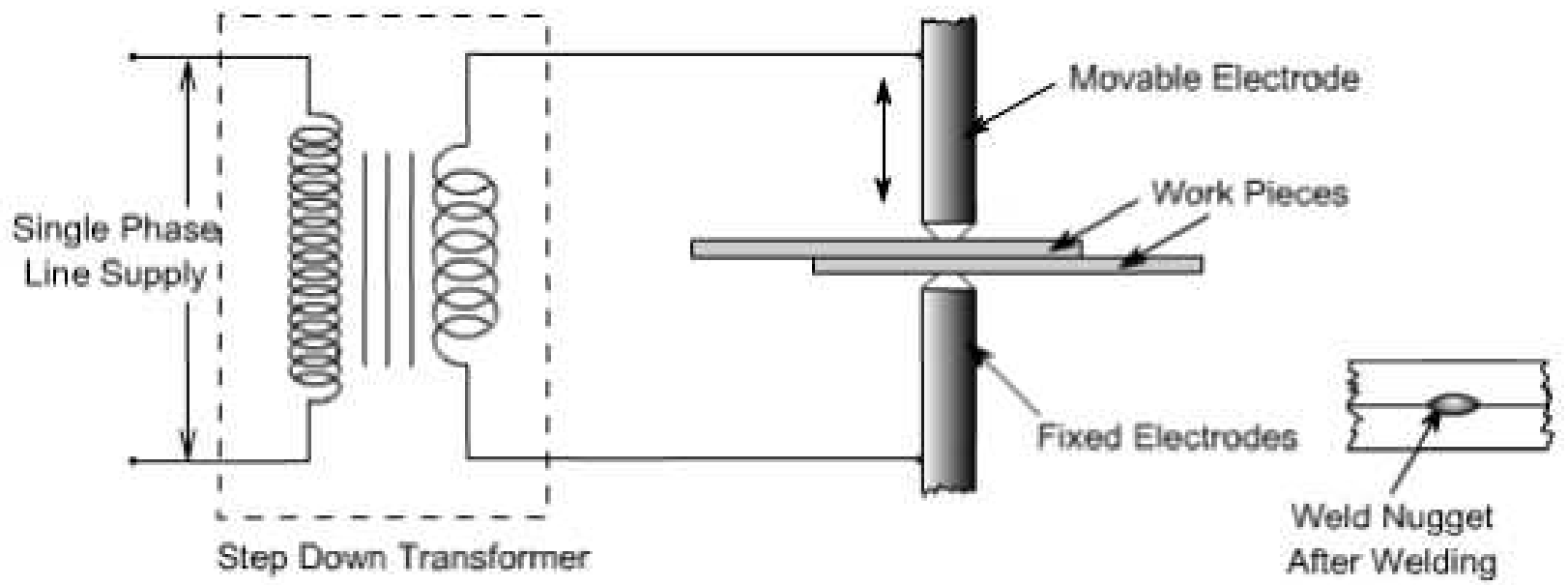

Figure 1

AC is supply is most distinction out of these three in view of its straightforwardness. DC supply can utilized where substantial measure of current is required. in this procedure there are two terminals one of which is stationary and the other is portable. the sheets which should be welded are held between the cathodes with weight. at the point when the supply of current begins through the plates[12].

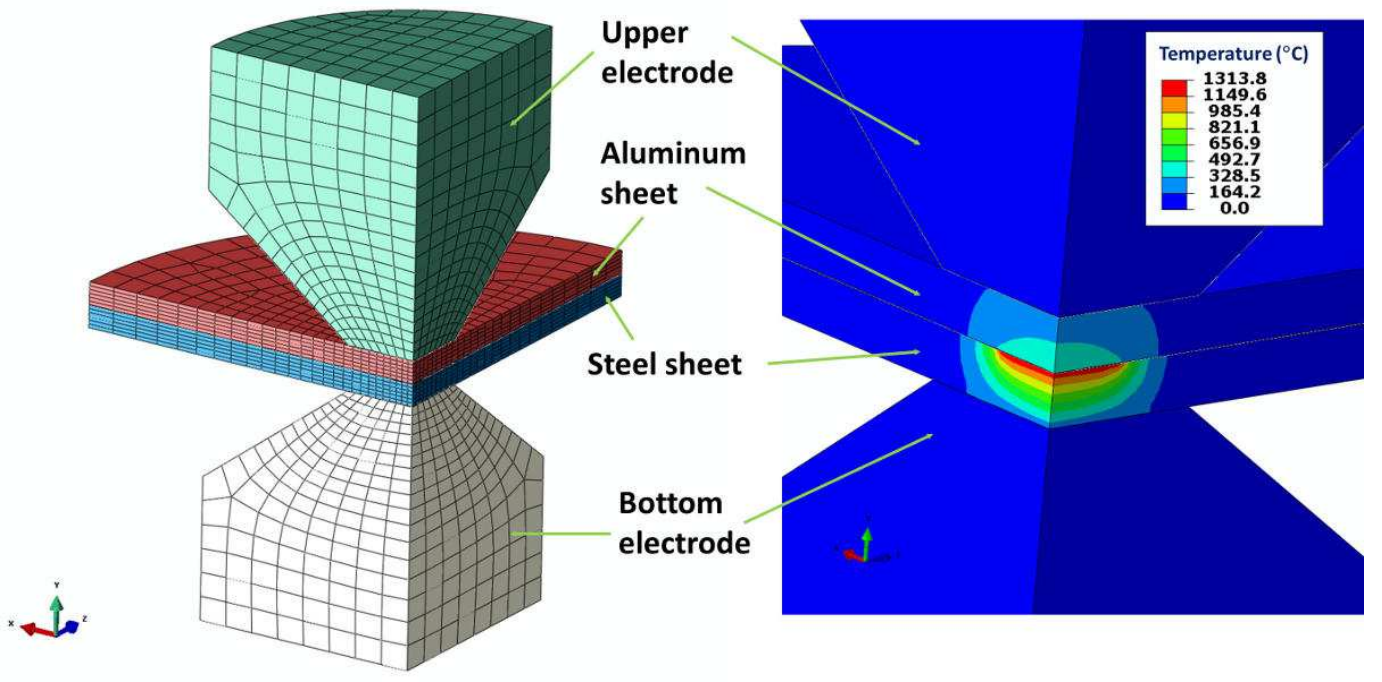

Figure 2

AC is supply is most distinction out of these three in view of its straightforwardness. DC supply can utilized where substantial measure of current is required. in this procedure there are two terminals one of which is stationary and the other is portable. The sheets which should be welded are held between the cathodes with weight. At the point when the 
supply of current begins through the plates.

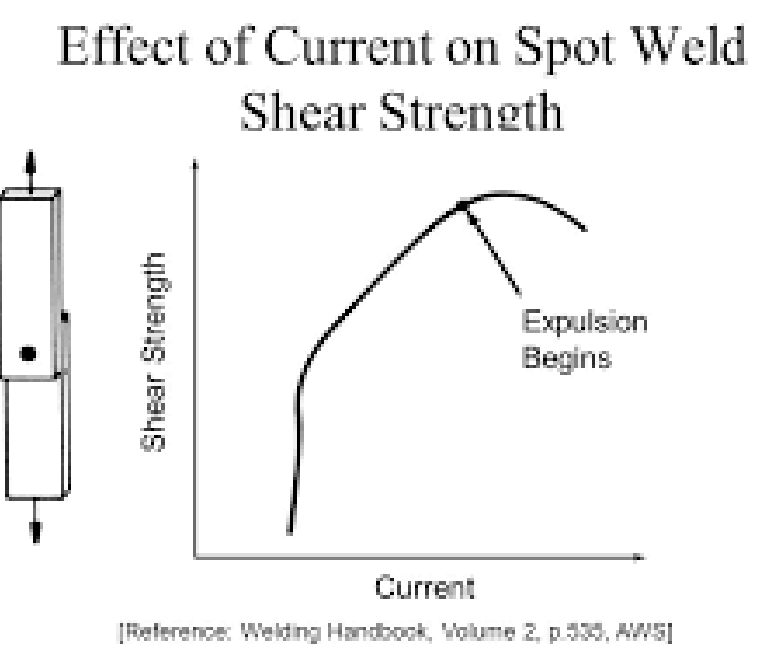

Figure 3

Spot welding on the off chance that we builds the esteem and keep up the offset with the power and voltage the estimation of shear quality expands same goes for the ideal opportunity for which the present goes through the interface[13,14]. it has an ideal incentive for good quality join. the choice of how much weight ought to be connected relies on the properties of the metal which should be welded if huge measure of weight is connected on delicate metal it can result in space which can result in the flimsier joint arrangement yet the ideal measure of weight can result in legitimate piece development. the other sort of obstruction welding is crease welding. in this procedure covering sheets are held between rollers which act like anodes. at the point when supply of current is turned on it results in warmth age locally around the interface. in this procedure the pieces are covering one another and creating consistent welding[15,16]. It will be called constant weld just when the pieces are over lapping each other over half. in the event that the administrator needs less covering he can utilize the throbbing current. tantamount to this procedure sounds it has a few inconveniences like the hardware required to play out the activity are cumbersome and costly. 


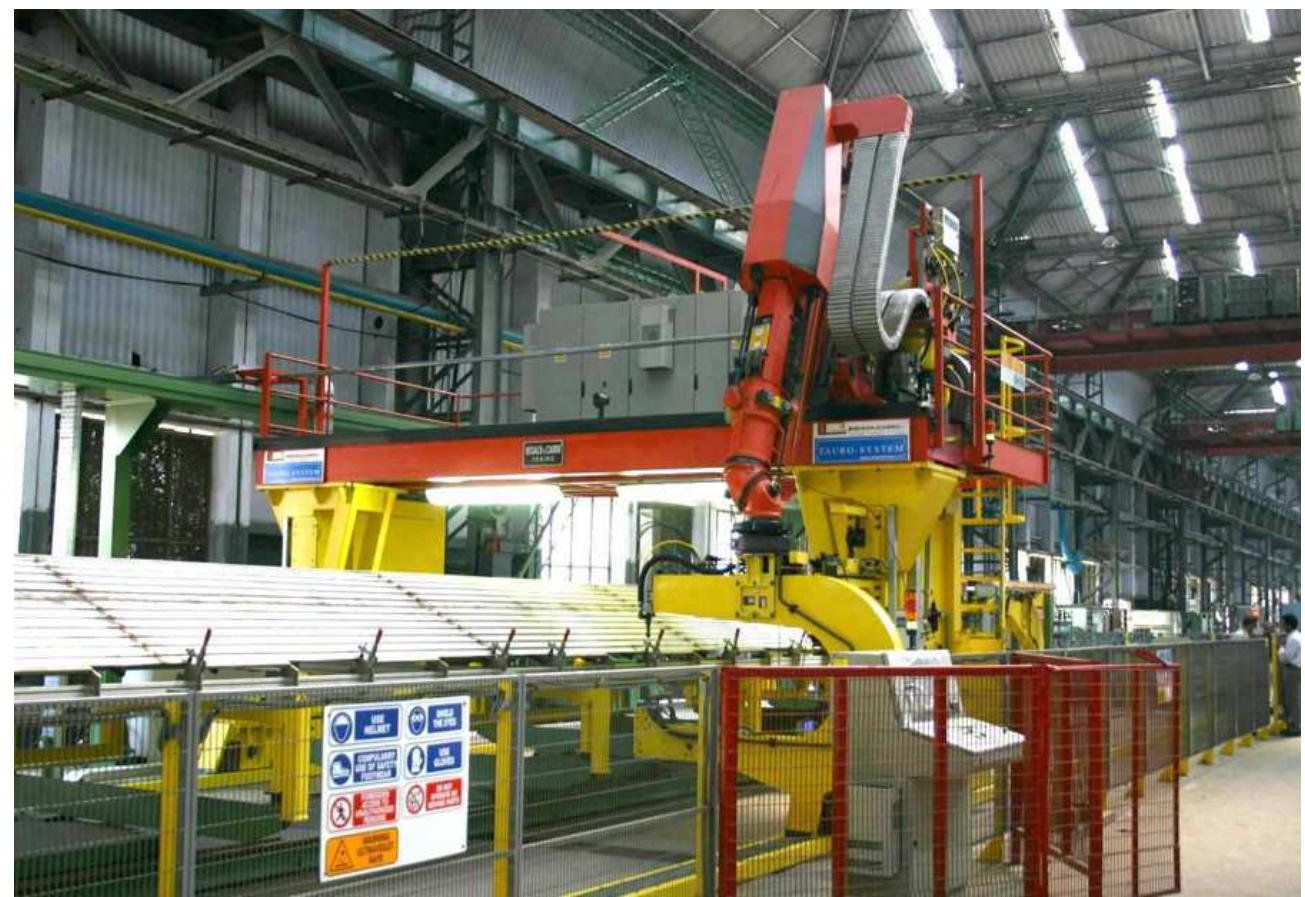

Figure 4

The one other major disadvantage is that the welding can be only performed on the sheets which have thickness less than $3 \mathrm{~mm}$.

\section{CONCLUSIONS}

Resistance welding frames are weight welding shapes in which overpowering current is enjoyed a reprieve through the region of interface of metals to be joined. These methodology differentiate from other welding frames in the thankfulness that no changes are used, and filler metal every so often used. All deterrent welding exercises are customized and, along these lines, all technique factors are preset and taken care of predictable. Warmth is made in restricted zone which is adequate to warm the metal to satisfactory temperature, so the parts can be joined with the use of weight. Weight is associated through the anodes

In any case, although the oneshot welding frameworks offer an all out welding time a lot quicker than the absolute welding time for GMAW frameworks, they should be finished in one welding station and the basic way activities can be any longer due to the slower setup and the requirement for postweld tasks, for example, streak evacuation. It has regularly been hard proportional up to these procedures to substantial breadth funnels. In any case, the power pillar forms don't experience the ill effects of similar issues, since multi-pass and multi head welding is conceivable with laser and electron bar welding. These procedures may, in like manner, be utilized to halfway total a weld and an elective procedure utilized for fill passes. Hence, the power-bar forms are as of now being more effectively created than the one-shot procedures.

\section{REFERENCES}

1. S. Ito, H. T. Fujii, R. Hayasaka, Y. S. Sato, and H. Hashizume, "Comparison of Heat Assisted Lap Joints of High-Temperature Superconducting Tapes With Inserted Indium Foils,” IEEE Trans. Appl. Supercond., vol. 29, no. 5, Aug. 2019.

2. P. Lacki, A. Derlatka, and J. Winowiecka, "Analysis of the composite I-beam reinforced with PU foam with the addition of chopped glass fiber," Compos. Struct., vol. 218, pp. 60-70, Jun. 2019. 
3. S. Chandra-ambhorn and P. Saranyachot, "Effect of the H-2 content in shielding gas on the microstructure and oxidation resistance of Fe-15.7 wt.\% Cr-8.5 wt.\% Mn steel GTA welds,” J. Mater. Process. Technol., vol. 268, pp. 18-24, Jun. 2019.

4. F. Dittrich, J. Kaars, B. Masek, S. Jenicek, M. F.-X. Wagner, and P. Mayr, "HAZ characterization of welded $42 \mathrm{SiCr}$ steel treated by quenching and partitioning," J. Mater. Process. Technol., vol. 268, pp. 37-46, Jun. 2019.

5. A. Evangeline and P. Sathiya, "Cold metal arc transfer (CMT) metal deposition of Inconel 625 superalloy on $316 \mathrm{~L}$ austenitic stainless steel: microstructural evaluation, corrosion and wear resistance properties,” Mater. Res. EXPRESS, vol. 6, no. 6, Jun. 2019.

6. H. Li, J. Zhang, and X. Wang, "Microstructure and mechanical properties of TIG welded-brazed AZ61 Mg alloy and mild steel joints with and without interlayer," Mater. Res. EXPRESS, vol. 6, no. 6, Jun. 2019.

7. Jassim, A. O., Jazzy, J. H., \& Mohammed, M. Study the Effect of Addition Copper Layer for Spot Welding of LCS-304LSS Joints.

8. J. Liu, W. Pan, Y. Liu, and Y. Wang, "Effect of graphene on corrosion resistance of micro-arc oxidation coatings on 6061/7075 dissimilar laser-MIG hybrid welded joint," Mater. Res. EXPRESS, vol. 6, no. 6, Jun. 2019.

9. S. S. Sravanthi, S. G. Acharyya, K. V. P. Prabhakar, and G. Padmanabham, "Integrity of 5052 Al-mild steel dissimilar welds fabricated using MIG-brazing and cold metal transfer in nitric acid medium,” J. Mater. Process. Technol., vol. 268, pp. 97106, Jun. 2019.

10. W. C. Tucker, P. Lockhart, and E. Guzas, "Evaluating Sensitized Chromium Steel Alloys with Induction Infrared Thermography," J. Nondestruct. Eval., vol. 38, no. 2, Jun. 2019.

11. Q. Wang, Y. Zhou, J. Zhou, and G. Zhang, "Microstructure and properties of PTA sprayed 310/WC composite coating," Mater. Res. EXPRESS, vol. 6, no. 6, Jun. 2019.

12. W. Wang et al., "Fatigue behavior investigation on dissimilar aluminum alloy ring welded joints in a new type sandwich highpressure shell,” Mater. Res. EXPRESS, vol. 6, no. 6, Jun. 2019.

13. K. Zhou and P. Yao, "Overview of recent advances of process analysis and quality control in resistance spot welding," Mech. Syst. Signal Process., vol. 124, pp. 170-198, Jun. 2019.

14. J. Bonilla, L. M. Bezerra, and E. Mirambell, "Resistance of stud shear connectors in composite beams using profiled steel sheeting," Eng. Struct., vol. 187, pp. 478-489, May 2019.

15. D. Brassard, M. Dube, and J. R. Tavares, "Resistance welding of thermoplastic composites with a nanocomposite heating element,” Compos. PART B-ENGINEERING, vol. 165, pp. 779-784, May 2019.

16. Yunus, M. О. Н. A. М. М. E. D., \& Alsoufi, M. S. (2015). A statistical analysis of joint strength of dissimilar aluminium alloys formed by friction stir welding using taguchi design approach, anova for the optimization of process parameters. IMPACT: International Journal of Research in Engineering \& Technology (IMPACT: IJRET), 3(7), 63-70.

17. J. Zhao et al., "Microstructure and mechanical properties of Co-based alloy coatings fabricated by laser cladding and plasma arc spray welding," J. Alloys Compd., vol. 785, pp. 846-854, May 2019.

18. C. Xuesen and S. Gang, "Cyclic tests on high strength steel flange-plate beam-to-column joints," Eng. Struct., vol. 186, pp. 564-581, May 2019. 